\title{
A novel cost-effective technology to convert sucrose and homocelluloses in sweet sorghum stalks into ethanol
}

Jihong $\mathrm{Li}^{1,2}$, Shizhong $\mathrm{Li}^{1,2^{*}}$, Bing Han ${ }^{1,2}$, Menghui $\mathrm{Yu}^{1,2}$, Guangming $\mathrm{Li}^{1,2}$ and Yan Jiang ${ }^{1,2}$

\begin{abstract}
Background: Sweet sorghum is regarded as a very promising energy crop for ethanol production because it not only supplies grain and sugar, but also offers lignocellulosic resource. Cost-competitive ethanol production requires bioconversion of all carbohydrates in stalks including of both sucrose and lignocellulose hydrolyzed into fermentable sugars. However, it is still a main challenge to reduce ethanol production cost and improve feasibility of industrial application. An integration of the different operations within the whole process is a potential solution.

Results: An integrated process combined advanced solid-state fermentation technology (ASSF) and alkaline pretreatment was presented in this work. Soluble sugars in sweet sorghum stalks were firstly converted into ethanol by ASSF using crushed stalks directly. Then, the operation combining ethanol distillation and alkaline pretreatment was performed in one distillation-reactor simultaneously. The corresponding investigation indicated that the addition of alkali did not affect the ethanol recovery. The effect of three alkalis, $\mathrm{NaOH}, \mathrm{KOH}$ and $\mathrm{Ca}(\mathrm{OH})_{2}$ on pretreatment were investigated. The results indicated the delignification of lignocellulose by $\mathrm{NaOH}$ and $\mathrm{KOH}$ was more significant than that by $\mathrm{Ca}(\mathrm{OH})_{2}$, and the highest removal of xylan was caused by $\mathrm{NaOH}$. Moreover, an optimized alkali loading of $10 \%(\mathrm{w} / \mathrm{w}$ DM) $\mathrm{NaOH}$ was determined. Under this favorable pretreatment condition, enzymatic hydrolysis of sweet sorghum bagasse following pretreatment was investigated. $92.0 \%$ of glucan and $53.3 \%$ of xylan conversion were obtained at enzyme loading of $10 \mathrm{FPU} / \mathrm{g}$ glucan. The fermentation of hydrolyzed slurry was performed using an engineered stain, Zymomonas mobilis TSH-01. A mass balance of the overall process was calculated, and $91.9 \mathrm{~kg}$ was achieved from one tonne of fresh sweet sorghum stalk.

Conclusions: A low energy-consumption integrated technology for ethanol production from sweet sorghum stalks was presented in this work. Energy consumption for raw materials preparation and pretreatment were reduced or avoided in our process. Based on this technology, the recalcitrance of lignocellulose was destructed via a cost-efficient process and all sugars in sweet sorghum stalks lignocellulose were hydrolysed into fermentable sugars. Bioconversion of fermentable sugars released from sweet sorghum bagasse into different products except ethanol, such as butanol, biogas, and chemicals was feasible to operate under low energy-consumption conditions.
\end{abstract}

Keywords: Sweet sorghum stalks, Alkaline pretreatment, Solid-state fermentation, Bioethanol

\footnotetext{
*Correspondence: szli@mail.tsinghua.edu.cn

${ }^{1}$ Institute of Nuclear and New Energy Technology, Tsinghua University, Beijing 100084, People's Republic of China

${ }^{2}$ Beijing Engineering Research Center of Biofuels, MOST-USDA joint research center for biofuels, Beijing 100084, People's Republic of China
} 


\section{Background}

Increased fossil fuel consumption has resulted in a series of social and environmental problems, such as the crisis of oil, global climate change and the emission of greenhouse gas. Sustainable and clean renewable energy as an alternative to fossil fuels has attracted extensive attention worldwide. Among various renewable energies, bioethanol is an important renewable liquid fuel due to its high octane number and heat of vaporization. Bioethanol is also less volatile than gasoline, has a lower photochemical reactivity in the atmosphere, and smog formation from emissions of pure ethanol can be less than from gasoline [1].

Sweet sorghum is a high photosynthetic-efficiency energy crop with high biomass (20 to 30 dry tonnes/ha) and sugar-yielding (16 to $18 \%$ fermentable sugar in juice) [2]. It is also the only crop that provides grain and sugar, and a lignocellulosic biomass resource. Sweet sorghum has several primary advantages, such as (1) its adaptability to diverse climate zones and soil conditions (salinity, alkalinity and drought); (2) low requirement of fertilizers; (3) high water-usage efficiency compared with more conventional crops (1/3 of sugarcane and $1 / 2$ of corn), and (4) short growth period (3 to 5 months) [3]. Based on these advantages, sweet sorghum can be planted on marginal lands. It will avoid competing for land against other cultures that are used for food production [4]. For these reasons, sweet sorghum has been regarded as an alcohol fuel crop with a promising future [5-7]. In fact, ethanol production from non-structural carbohydrates in sweet sorghum stalks is not difficult. There are two major kinds of technology to convert fermentable sugars to ethanol from sweet sorghum, one is liquid fermentation $[4,8,9]$, the other is solid-state fermentation [10-12]. However, because there are approximately equal quantities of soluble and insoluble carbohydrates in sweet sorghum stalks [13], the major challenge for large-scale application of bioethanol production from sweet sorghum is how to deal with these lignocellulosic fractions (usually called bagasse). Cost-competitive ethanol production from sweet sorghum requires the bioconversion of all carbohydrates, including that of the sugar and lignocellulosic fraction, into ethanol.

Due to the recalcitrant nature of lignocellulosic materials, efficient bioconversion of sweet sorghum bagasse requires effective pretreatment to liberate cellulose from its physical seal and open up its crystalline structure before enzymatic hydrolysis can take place [14]. Although a range of chemical, physical and biological processes have been configured to release structural sugars from lignocellulose, they have to face the challenges of cost, infrastructure needs and technological breakthroughs [15]. An ideal pretreatment should have features as follows: (1) rendering high accessibility of biomass substrates to cellulases; (2) low capital and operational cost; (3) minimized size reduction of raw materials, and
(4) producing low amounts of inhibitors to the enzymes and the fermentative microorganisms [16]. Compared to other pretreatment technologies, alkaline pretreatment processes generally utilize lower temperatures, pressures and residence times, and produce lower concentration of inhibitors [17]. Sodium hydroxide, potassium hydroxide and lime are usually used as an alkali reagent. The key role of alkaline is to partially remove lignin and hemicellulose in the biomass by disrupting the ester bonds cross-linking between lignin and xylan, thereby increasing the porosity of the biomass and resulting in cellulose and hemicellulose enriched fractions [18-20]. Enzymatic hydrolysis of sweet sorghum bagasse has been studied to some extent, and high enzymatic digestibility of sweet sorghum bagasse has also been reported [19-23]. However, the ethanol production cost is still high due to the complexity of the normal technology.

In the present study, a low energy-consumption and cost-efficient integrated process combining advanced solid-state fermentation technology (ASSF), alkaline pretreatment and $\mathrm{C} 5-\mathrm{C} 6$ co-fermentation in a whole process was configured. The effects of three alkalis, sodium hydroxide $(\mathrm{NaOH})$, potassium hydroxide $(\mathrm{KOH})$ and calcium hydroxide $\left(\mathrm{Ca}(\mathrm{OH})_{2}\right)$ on the ethanol recovery, pretreatment and enzymatic digestibility of sweet sorghum bagasse were investigated. In order to study the total ethanol yield of the overall process, C5-C6 co-fermentation of hydrolysed slurry was performed using an engineer strain Zymomonas mobilis (Z. mobilis) TSH-O1.

\section{Results and discussion}

\section{Novel process flow of ethanol production from sweet sorghum stalks}

Sweet sorghum shows a potential for ethanol production because its stalk is rich in both non-structural carbohydrates (sucrose, glucose and fructose) and structural carbohydrates (cellulose and hemicellulose) [20]. Costcompetitive ethanol production from sweet sorghum is challenged by the bioconversion of all carbohydrates from sugar and lignocellulose fractions into ethanol. The extraction of juice from the stalks is normally applied prior to pretreatment to prevent soluble sugar degradation. However, the squeezing operation needs high energy consumption. ASSF was studied in our previous work [21], and a demonstrated plant has been built up in Inner Mongolia province, China. The research on ASSF technology demonstrated that ASSF is a cost-efficient process, which can convert non-structural sugars to ethanol by anaerobic fermentation using the crushed sweet sorghum stalks directly in a rotatory drum fermenter [6,11]. After fermentation, almost all the non-structural sugars were consumed. The ethanol produced in the solid state fermentation step remained in the fermented bagasse. The ethanol separation was achieved by heating this fermented 
bagasse with low-pressure steam in a distillation stripper. In our ASSF technology, ethanol distillation from fermented bagasse was carried out at approximately $100^{\circ} \mathrm{C}$, which is the temperature required for alkaline pretreatment. Therefore, the implementation of alkaline pretreatment is feasible, provided that the alkali does not negatively influence the distillation process. After this special distillation operation with alkali, the recalcitrant structure of sweet sorghum bagasse was disrupted.

The process flow schematic is shown in Figure 1. The fresh sweet sorghum was crushed by a pulverizer into particles 1 to $2 \mathrm{~mm}$ in diameter and 3 to $20 \mathrm{~mm}$ in length. Then the crushed sweet sorghum stalks, completely blended with $10 \%$ (v/w) of Saccharomyces cerevisiae TSH1 seed culture (about $25 \mathrm{~g} / \mathrm{L}$, dry weight), were added in a rotatory drum fermenter. The solid-state fermentation was performed for $24 \mathrm{~h}$ at $30^{\circ} \mathrm{C}$ with a rotary speed of $0.5 \mathrm{rpm}$. After the fermentation finished, the fermented bagasse containing ethanol was completely mixed with a certain volume of concentrated alkali solution. The fermented bagasse with alkali was transferred into a distillation stripper. The sugar-based ethanol remaining in the fermented bagasse was separated and collected by distillation. After distillation with alkali, the black liquor fraction, rich in lignin, was removed by centrifugation and the residual solids were washed with water, followed byfurther enzymatic hydrolyzation by a commercial cellulase at a $15 \%(\mathrm{w} / \mathrm{w})$ solid loading. After $72 \mathrm{~h}$ enzymatic hydrolysis, the enzymatic slurry was anaerobically fermented using an engineered stain of $Z$. mobilis TSH-01. The cellulosic ethanol was separated from the fermentation broth.
From Figure 1, it is obvious that the integrated process retains all the advantages of solid-state fermentation technology, such as lower energy consumption for biomass material preparation and less waste water. Moreover, the equipment and the extra energy and time consumption for pretreatment was avoided by combining distillation and alkaline pretreatment in one step. Compared with ethanol production technology using sweet sorghum bagasse (obtained after extraction of juice from sweet sorghum stalks), this integrated technology significantly reduced energy consumption and the investment of infrastructure needs of pretreatment. Moreover, alkalinepretreated bagasse partially retained hemicellulose, increasing the potential fermentable sugars compared to acid-based pretreatments.

\section{Influence of alkali in sugar-based ethanol distillation}

In order to study the influence of alkali in ethanol distillation, an ethanol distillation experiment was carried out with addition of $\mathrm{NaOH}$. The ethanol distillation rate and ethanol recovery yield were investigated, and the results are shown in Figure 2 (the fermented bagasse without $\mathrm{NaOH}$ as a control).

The dynamic ethanol concentration profile obtained from the fermented bagasse with $10 \%(\mathrm{w} / \mathrm{w}$ dry mass (DM)) $\mathrm{NaOH}$ was similar to the control. In the presence of $\mathrm{NaOH}$, the ethanol recovery rate was slightly lower than that without alkali. It took 24 minutes to obtain $99 \%$ of ethanol-recovery yield in the presence of $\mathrm{NaOH}$, and 17 minutes in the absence of alkali. The ethanol content and recovery yield of fermented sweet sorghum

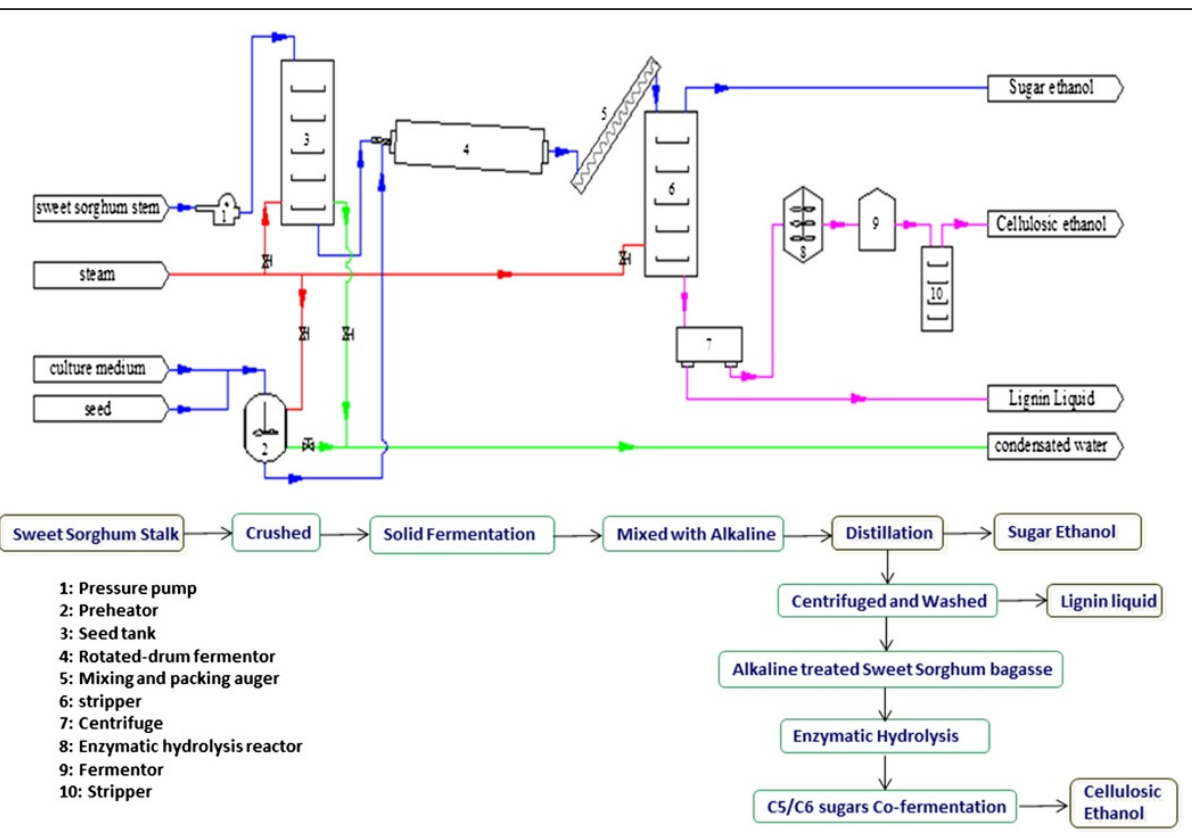

Figure 1 Process flow scheme of the novel cost-efficient integrated processes for ethanol production from sweet sorghum stalks. 


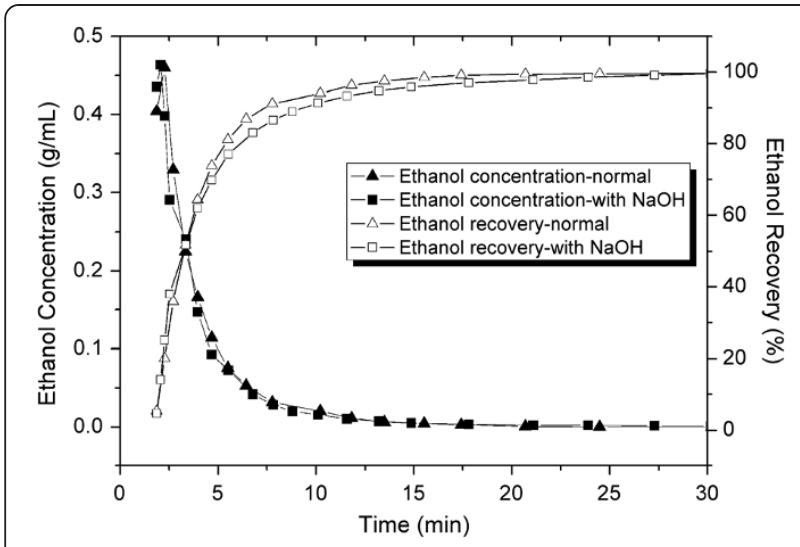

Figure 2 Dynamic ethanol distillation profile of fermented sweet sorghum bagasse treated with $10 \%$ (w/w dry mass) sodium hydroxide. $\mathrm{NaOH}$, sodium hydroxide.

bagasse is listed in Table 1 . The results show that the ethanol content of fermented bagasse slightly decreased from 6.01 to $5.69 \mathrm{~g}$ per $100 \mathrm{~g}$ wet bagasse after mixing with $\mathrm{NaOH}$, resulting from the release of ethanol during the mix operation. The loss of ethanol was about $3.4 \%$, attributed to the mixed operation by hand in an open vessel in the laboratory. In practice, the loss of ethanol can be avoided by conducting the mixing operation in closed equipment. The ethanol recovery yield of bagasse with $\mathrm{NaOH}$ is $99.5 \%$, equaling that of the control. This result demonstrated that ethanol-recovery yield was not affected by addition of alkali.

\section{Influence of alkali loading in the composition of sweet sorghum bagasse}

$\mathrm{NaOH}, \mathrm{KOH}$, ammonia and lime are alkali reagents commonly investigated in alkaline pretreatment of lignocellulosic biomass. Due to the volatility of ammonia, it is released quickly at $100^{\circ} \mathrm{C}$, so it cannot react completely with lignocellulosic substrates during the ethanol distillation. For this reason, ammonia was excluded from our work. The influence of other three alkali reagents in pretreatment was investigated by preliminary distillation experiments due to the limitation of the available amounts of fermented sweet sorghum bagasse. The pretreatment temperature was fixed at $100^{\circ} \mathrm{C}$ by ethanol distillation. In addition, to achieve high ethanol-recovery yield, distillation should be carried out for more than 24 minutes to achieve ethanol recovery yield of $99 \%$. Efficient alkaline pretreatment time of sweet sorghum bagasse has been reported to be in the range of 30 minutes to $100 \mathrm{~h}[18,19,22]$. To balance the requirement of distillation with pretreatment, the distillation duration was set at 30 minutes. The intensity of pretreatment increased with increasing alkali loading from 0.83 to $6.67 \mathrm{mmol} / \mathrm{g}$ of dry biomass. The alkali loading was commonly expressed in term of $\mathrm{g} / \mathrm{g}$ biomass in the study in which only one alkali was investigated. However, the stoichiometric ratio was not shown directly using this unit when there were several different alkalis, so the alkali loading in this work was expressed in terms of $\mathrm{mmol} / \mathrm{g}$ of dry biomass, which refers to the ratio of the amount of alkali to dry weight of sweet sorghum bagasse.

Table 2 summarizes the solid recovery yield and the compositions of sweet sorghum bagasse following pretreatment with different alkali loading.

As expected, lime performed worse than $\mathrm{NaOH}$ and $\mathrm{KOH}$. During alkaline pretreatment, the cleavage of hydrolysable linkages, such as $\alpha$ - and $\beta$-aryl ethers in lignin and glycosidic bonds in carbohydrates, constitute the primary reactions that lead to the dissolution of lignin and carbohydrate with lower alkali stability [23]. Removal of hemicellulose and lignin, however, varied significantly depending on the pretreatment conditions (Figure 3 and Figure 4). The efficiency of delignification of the strong alkalis, $\mathrm{NaOH}$ and $\mathrm{KOH}$, was significantly better than that of the weak alkali, $\mathrm{Ca}(\mathrm{OH})_{2}$. With increased loading of strong alkalis, the lignin removal increased until the alkali loading of $2.5 \mathrm{mmol} / \mathrm{g}$ of dry biomass; above this value the lignin removal did not increase significantly. The compositional analysis showed that almost all the lignin contents of bagasse following alkaline pretreatment were less than $10 \%$ when the loading of strong alkali of more than

Table 1 Ethanol distillation of the fermented sweet sorghum bagasse

\begin{tabular}{|c|c|c|c|c|}
\hline & \multicolumn{2}{|c|}{ Normal distillation } & \multicolumn{2}{|c|}{ Distillation with $10 \%$ (w/w DM) $\mathrm{NaOH}$} \\
\hline & Before & After & Before & After \\
\hline Sample mass for distillation ( $\mathrm{g}$ ) & 4000 & 4962 & 4076 & 4828 \\
\hline Ethanol content in the sample $\left(\mathrm{g} / 100 \mathrm{~g} \mathrm{WM}^{\mathrm{a}}\right)$ & 6.01 & 0.02 & 5.69 & 0.02 \\
\hline Ethanol in sample $(\mathrm{g})$ & 240.6 & 0.9 & 231.9 & 0.9 \\
\hline Recovered ethanol $\mathrm{l}^{\mathrm{b}}(\mathrm{g})$ & & 239.0 & & 230.8 \\
\hline Ethanol recovery (\%) & & 99.5 & & 99.5 \\
\hline
\end{tabular}

${ }^{\mathrm{a} W M}$ represents the wet mass of sweet sorghum bagasse; ${ }^{\mathrm{b}}$ The mass of recovered ethanol is calculated by the concentration $(\mathrm{g} / \mathrm{mL})$ of the distillate multiplied by the volume $(\mathrm{mL})$ of the distillate. $\mathrm{DM}$, dry mass. 
Table 2 Sweet sorghum bagasse recovered after distillation combined with alkaline pretreatment and main composition

\begin{tabular}{|c|c|c|c|c|c|}
\hline \multirow[t]{2}{*}{ Alkali } & \multirow{2}{*}{$\begin{array}{l}\text { Alkali loading } \\
\text { (mmol/g dry } \\
\text { biomass) }\end{array}$} & \multirow[t]{2}{*}{ Solid recovery (\%) } & \multicolumn{3}{|c|}{ Composition (\%) } \\
\hline & & & Glucan & Xylan & Lignin \\
\hline Untreated & NA & NA & $30.33 \pm 0.34$ & $20.93 \pm 0.23$ & $20.46 \pm 0.64$ \\
\hline $\mathrm{NaOH}$ & 0.83 & $72.8 \pm 1.3$ & $41.22 \pm 0.12$ & $28.94 \pm 0.78$ & $15.93 \pm 0.27$ \\
\hline $\mathrm{NaOH}$ & 1.67 & $61.8 \pm 2.4$ & $48.62 \pm 0.21$ & $39.07 \pm 0.56$ & $13.62 \pm 0.43$ \\
\hline $\mathrm{NaOH}$ & 2.50 & $57.9 \pm 1.7$ & $51.31 \pm 0.75$ & $32.26 \pm 0.37$ & $11.21 \pm 0.29$ \\
\hline $\mathrm{NaOH}$ & 3.33 & $51.8 \pm 3.9$ & $57.25 \pm 0.35$ & $32.38 \pm 0.74$ & $8.21 \pm 0.25$ \\
\hline $\mathrm{NaOH}$ & 4.17 & $51.3 \pm 3.3$ & $57.69 \pm 0.55$ & $30.81 \pm 0.63$ & $7.34 \pm 0.36$ \\
\hline $\mathrm{NaOH}$ & 5.00 & $49.3 \pm 2.2$ & $60.04 \pm 0.81$ & $29.34 \pm 0.39$ & $7.27 \pm 0.20$ \\
\hline $\mathrm{NaOH}$ & 6.67 & $47.7 \pm 0.9$ & $61.63 \pm 0.22$ & $27.55 \pm 0.49$ & $7.86 \pm 0.83$ \\
\hline $\mathrm{KOH}$ & 0.83 & $71.5 \pm 1.8$ & $42.01 \pm 0.33$ & $26.34 \pm 0.52$ & $16.94 \pm 0.31$ \\
\hline $\mathrm{KOH}$ & 1.67 & $62.8 \pm 3.1$ & $47.84 \pm 0.51$ & $29.10 \pm 0.16$ & $13.23 \pm 0.58$ \\
\hline $\mathrm{KOH}$ & 2.50 & $60.7 \pm 1.6$ & $49.28 \pm 0.73$ & $29.28 \pm 0.63$ & $9.92 \pm 0.56$ \\
\hline $\mathrm{KOH}$ & 3.33 & $58.2 \pm 1.2$ & $51.07 \pm 0.23$ & $28.62 \pm 0.04$ & $8.01 \pm 0.72$ \\
\hline $\mathrm{KOH}$ & 4.17 & $51.9 \pm 2.4$ & $57.10 \pm 0.95$ & $30.02 \pm 0.77$ & $6.50 \pm 0.25$ \\
\hline $\mathrm{KOH}$ & 5.00 & $51.5 \pm 0.7$ & $57.55 \pm 0.64$ & $29.43 \pm 0.19$ & $7.02 \pm 0.28$ \\
\hline $\mathrm{KOH}$ & 6.67 & $50.5 \pm 2.1$ & $57.97 \pm 0.63$ & $26.97 \pm 0.83$ & $7.26 \pm 0.46$ \\
\hline $\mathrm{Ca}(\mathrm{OH})_{2}$ & 0.83 & $78.3 \pm 1.2$ & $38.33 \pm 0.76$ & $23.89 \pm 0.36$ & $16.72 \pm 0.39$ \\
\hline $\mathrm{Ca}(\mathrm{OH})_{2}$ & 1.67 & $81.7 \pm 0.8$ & $36.73 \pm 0.42$ & $23.18 \pm 0.73$ & $15.98 \pm 0.32$ \\
\hline $\mathrm{Ca}(\mathrm{OH})_{2}$ & 2.50 & $68.7 \pm 1.3$ & $43.59 \pm 0.33$ & $26.55 \pm 0.53$ & $13.64 \pm 0.17$ \\
\hline $\mathrm{Ca}(\mathrm{OH})_{2}$ & 3.33 & $69.2 \pm 0.5$ & $42.98 \pm 0.08$ & $26.85 \pm 0.71$ & $15.05 \pm 0.31$ \\
\hline $\mathrm{Ca}(\mathrm{OH})_{2}$ & 4.17 & $70.7 \pm 2.1$ & $41.95 \pm 0.55$ & $26.20 \pm 0.81$ & $14.52 \pm 0.48$ \\
\hline $\mathrm{Ca}(\mathrm{OH})_{2}$ & 5.00 & $71.3 \pm 1.7$ & $41.57 \pm 0.18$ & $25.82 \pm 0.31$ & $13.18 \pm 0.17$ \\
\hline $\mathrm{Ca}(\mathrm{OH})_{2}$ & 6.67 & $69.5 \pm 1.4$ & $42.14 \pm 0.38$ & $26.13 \pm 0.75$ & $13.51 \pm 0.42$ \\
\hline
\end{tabular}

$\mathrm{NaOH}$, sodium hydroxide; $\mathrm{KOH}$, potassium hydroxide; $\mathrm{Ca}(\mathrm{OH})_{2}$, calcium hydroxide; $\mathrm{NA}$, not applicable. All the data are shown as mean $\pm \mathrm{SD}$.
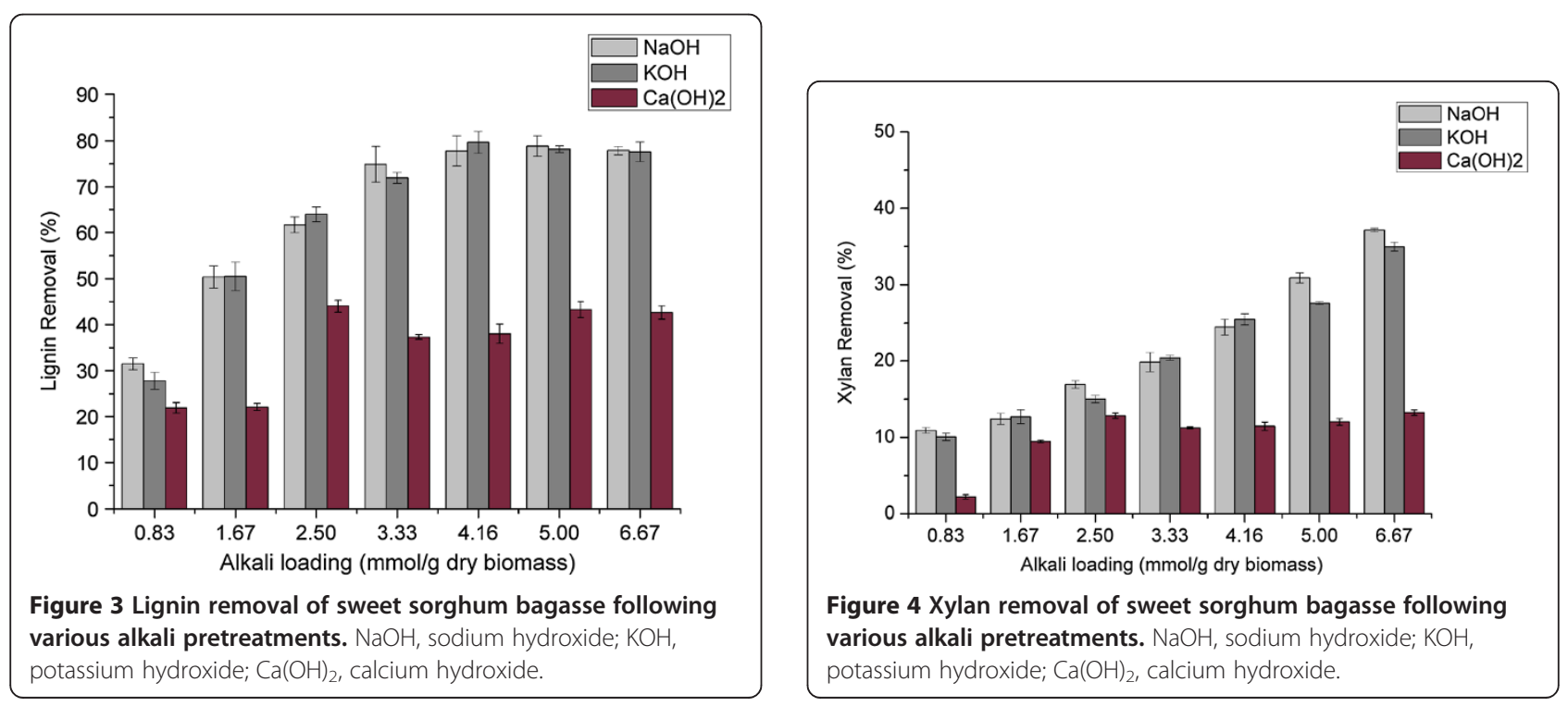
$2.5 \mathrm{mmol} / \mathrm{g}$ of dry biomass was used. Figure 3 shows that more than $70 \%$ of lignin was removed when the strong alkali loading was more than $3.33 \mathrm{mmol} / \mathrm{g}$ of dry biomass, whereas the highest lignin removal of bagasse treated with $\mathrm{Ca}(\mathrm{OH})_{2}$ was only $43.97 \%$ with loading of $2.5 \mathrm{mmol} / \mathrm{g}$ of dry biomass. Moreover, the results of compositional analysis showed that the lignin contents of bagasse were all more than $13 \%$ after $\mathrm{Ca}(\mathrm{OH})_{2}$ pretreatment. The result was in accordance with that of sugarcane bagasse treated with $0.40 \mathrm{~g} / \mathrm{g}$ of lime at $90^{\circ} \mathrm{C}$ for $53.1 \mathrm{~h}$, which resulted from the short pretreatment time [24]. Hence, pretreatment time is a crucial factor affecting the efficiency of lime pretreatment.

Cellulose was difficult to degrade under the alkaline condition [25], so the recovery yield of cellulose was more than $95 \%$ for all the samples following pretreatment. By increasing the intensity of the pretreatment, the cellulose content of bagasse increased gradually due to the removal of hemicellulose and lignin until the loading of $3.33 \mathrm{mmol} / \mathrm{g}$ of dry biomass. In accordance with the tendency of delignification, the cellulose content did not further increase significantly after the alkali loading used in the pretreatment exceeded $3.33 \mathrm{mmol} / \mathrm{g}$ of dry biomass. $\mathrm{Ca}(\mathrm{OH})_{2}$ pretreatment appeared to have weak ability to increase the cellulose content because the pretreatment time was too short. The cellulose content of bagasse treated with $\mathrm{Ca}(\mathrm{OH})_{2}$ varied from 38.33 to $42.98 \%$, whereas that of bagasse treated with strong alkalis varied from 41.22 to $61.63 \%$ for $\mathrm{NaOH}$, and from 42.01 to $57.97 \%$ for $\mathrm{KOH}$.

The results of xylan removal are shown in Figure 4. With increasing concentration of strong alkalis, the removal of xylan increased linearly. Moreover, compared with $\mathrm{KOH}$ the hemicellulose had higher solubility in $\mathrm{NaOH}$ solution. The greatest xylan removal of $37.16 \%$ was caused by treatment with $\mathrm{NaOH}$ of $6.67 \mathrm{mmol} / \mathrm{g}$ of dry biomass, whereas it was $34.94 \%$ under $\mathrm{KOH}$ pretreatment. Compared with cellulose, the xylan content of bagasse following strong alkali pretreatment increased first to reach a peak, and then decreased gradually. The peak value occurred at alkali loading of 1.67 and $4.16 \mathrm{mmol} / \mathrm{g}$ of dry biomass for $\mathrm{NaOH}$ and $\mathrm{KOH}$, respectively. This result was attributed to more hemicellulose dissolving in the alkaline solution at high alkali concentration. In contrast, lime has poor ability to dissolve the hemicellulose, and only less than $14 \%$ of xylan was removed from the bagasse under our process condition. Similar to lignin removal, the results demonstrated that to achieve the desirable pretreatment efficiency, lime needed more pretreatment time due to its low reactivity.

\section{Pretreatment efficiency by enzymatic digestibility}

The glucan conversions obtained during enzymatic hydrolysis of bagasse pretreated with different alkali loading are shown in Figure 5. With increasing loading dose of strong alkalis $(\mathrm{NaOH}$ and $\mathrm{KOH})$, the glucan conversion of sweet sorghum bagasse following pretreatment increased first to reach a peak, and then decreased slightly. The peak value of $84.96 \%$ was achieved by $\mathrm{NaOH}$ loading of $2.5 \mathrm{mmol} / \mathrm{g}$ of dry biomass, and $70.25 \%$ peak value was achieved by $\mathrm{KOH}$ loading of $4.16 \mathrm{mmol} / \mathrm{g}$ of dry biomass. Compared with strong alkalis, the highest glucan conversion of bagasse treated with lime was only $18.87 \%$. This result was attributed to low removal of lignin and hemicellulose. In addition, enzymatic activity was affected by the high $\mathrm{pH}$ value of the hydrolysis solution, which resulted from the considerable residual calcium hydroxide after pretreatment due to the low solubility of calcium hydroxide.

Alkalis help to reduce recalcitrance of biomass through saponification of hemicellulose acetyl and lignin-carbohydrate complex linkages [26,27]. As reported by Chang and Holtzapple, an effective lignocellulose treatment process should remove all the acetyl groups and reduce the lignin content to about $10 \%$ in the treated biomass. Further lignin reduction incurs an extra cost; therefore, it is not justified by increments in glucan conversion [26]. Although the removal of hemicellulose could increase with increasing alkali loading, the glucan conversion did not increase linearly. Moreover, the high removal of xylan was negative to the efficient utility of sweet sorghum stalks. Taking into account solid recoveries and glucan conversion, the optimized alkali loading was determined to be $2.5 \mathrm{mmol}$ of $\mathrm{NaOH}$ per gram of dry biomass. Using this alkali loading, $61.66 \%$ of lignin was removed from the sweet sorghum bagasse, and a relatively high carbohydrate recovery of 91.56\% was achieved. Moreover, $\mathrm{NaOH}$ was a better choice and was used in the following experiments due to having a lower price than $\mathrm{KOH}$.

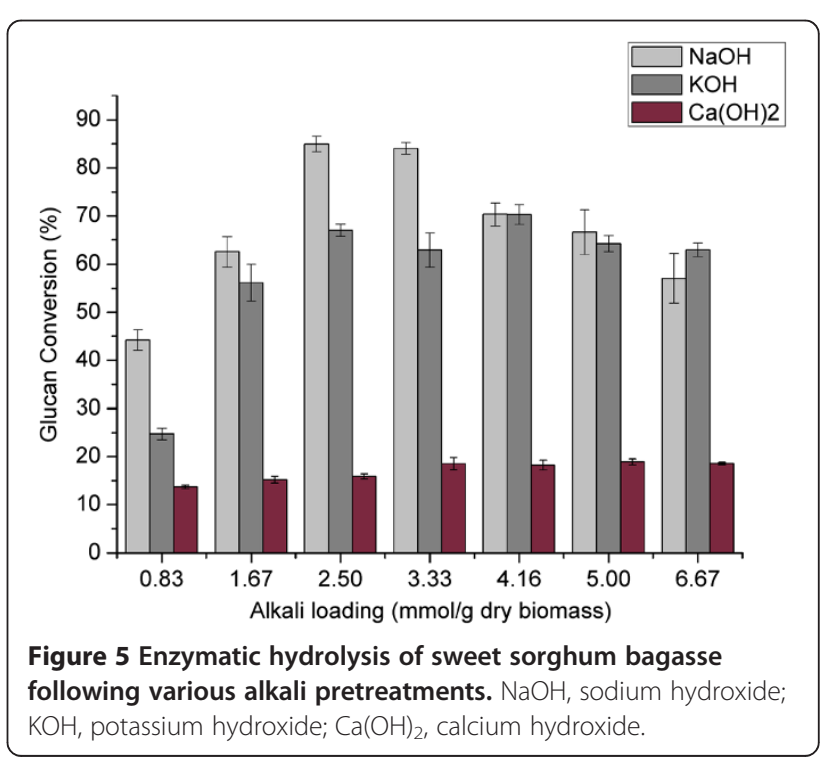




\section{Distillation combined with $\mathrm{NaOH}$ pretreatment operated in a distillation stripper}

In our designed process, the distillation of fermented sweet sorghum bagasse with alkali was performed in a distillation stripper. Fermented sweet sorghum bagasse (4 kg wet weight) was blended with $250 \mathrm{~mL}$ of $8 \mathrm{~mol} / \mathrm{L}$ $\mathrm{NaOH}$ solution and loaded in the distillation stripper for distillation. The moisture of the mixtures was about $80 \%$. The loading of $\mathrm{NaOH}$ was $2.5 \mathrm{mmol} / \mathrm{g}$ of dry biomass, which was optimized in the preliminary experiment of distillation combined with alkaline pretreatment. For convenience, this value was converted into $10 \%$ (w/w DM) $\mathrm{NaOH}$. Chen et al. reported that the enzymatic hydrolysis of carbohydrates substrates correlates better with biomass alkali loading than with alkali solution concentration [26]. The structural carbohydrate conversion increases with increasing alkali loading on dry biomass, whereas no correlation can be established between structural carbohydrates conversion and $\mathrm{NaOH}$ solution concentration [25]. This was attributed to the fact that sodium hydroxide was consumed in the pretreatment as a reactant rather than as a catalyst [28]. This revealed that the best loading used in the preliminary experiment was also adapted to the distillation combined with alkaline pretreatment performed in the distillation stripper, although the water content was different (the moisture of the bagasse was 76\%). The composition of bagasse following alkaline pretreatment performed in the distillation stripper is shown in Table 3. The carbohydrate content of bagasse, including glucan and $x y-$ lan, obtained from the distillation stripper was $57.28 \%$ and $32.86 \%$, respectively. These were both higher than those of bagasse obtained from the preliminary experiment. In contrast, the lignin content of $6.67 \%$ was lower than that in the preliminary experiment. The results demonstrated that using equal alkali loading, pretreatment in the distillation stripper was more efficient than that performed in the flask. This may be attributed to the higher heatefficiency of steam compared to an electric heater.

\section{Optimization of enzyme loading}

Commercial cellulose Cellic CTec3 was used in the enzymatic hydrolysis of sweet sorghum bagasse following

\section{Table 3 Composition of $10 \%$ (w/w dry mass) sodium hydroxide-treated sweet sorghum bagasse with ethanol distillation}

\begin{tabular}{lc}
\hline Composition & Content (\%) \\
\hline Glucan & $57.28 \pm 0.42$ \\
Xylan & $32.86 \pm 0.64$ \\
Acid soluble lignin (ASL) & $1.13 \pm 0.12$ \\
Acid insoluble lignin (AIL) & $5.54 \pm 0.22$ \\
Ash & $0.66 \pm 0.06$ \\
\hline
\end{tabular}

All data are shown as mean \pm SD. treatment with $10 \%(\mathrm{w} / \mathrm{w} \mathrm{DM}) \mathrm{NaOH}$ in a distillation stripper. Enzymatic hydrolysis experiments were performed at solid loading of $15 \%(\mathrm{w} / \mathrm{w})$ with enzyme doses of $4.5,6.0,7.5,9.0,11.0$, and 15,0 filter paper cellulase units (FPU)/g glucan, respectively. The results are shown in Figure 6. The results indicate that higher glucan conversion was obtained by increasing cellulase dosage up to $9 \mathrm{FPU} / \mathrm{g}$ of glucan. With further increasing enzyme loading, glucan conversion did not increase significantly, whereas the enzymatic hydrolysis rate increased continuously. That means more enzyme better decreases the hydrolysis time. Moreover, the speed of glucan conversion increased rapidly in the initial $12 \mathrm{~h}$, and this increment obviously slowed after $48 \mathrm{~h}$. However, to obtain relatively high glucose recovery, the enzymatic hydrolysis would be better carried out for $72 \mathrm{~h}$ because 4 to $10 \%$ of glucose recovery was still obtained during the last $24 \mathrm{~h}$. Cellic CTec3 is a state-of-the-art cellulase and hemicellulase complex reported by Novozymes, so reducing sugar including glucose and xylose was obtain after enzymatic hydrolysis of sweet sorghum treated with $10 \%$ (w/w DM) NaOH. The total reductive sugar concentrations at varying enzyme loading doses are shown in Figure $6 \mathrm{~b}$. When the enzyme loading exceeded $9 \mathrm{FPU} / \mathrm{g}$ of glucan, the concentration of total reductive sugar was more than $100 \mathrm{~g} / \mathrm{L}$ for $72 \mathrm{~h}$. The maximum reductive sugar concentration of $137.8 \mathrm{~g} / \mathrm{L}$ was achieved at an enzyme loading of $15 \mathrm{FPU} / \mathrm{g}$ for $120 \mathrm{~h}$. From an economic viewpoint, enzyme loading of $10 \mathrm{FPU} / \mathrm{g}$ glucan, and hydrolysis time of $72 \mathrm{~h}$ were adopted in our process. Under this condition, the final glucan and xylan conversion was 92.0 and $53.3 \%$ respectively, and the final concentration of reductive sugar was $116.9 \mathrm{~g} / \mathrm{L}$.

\section{C5-C6 anaerobic co-fermentation of hydrolysed slurry}

Although partial hemicellulose was removed in the distillation with alkali, there was still a considerable amount of hemicellulose left in the residual bagasse. The results show that there was $8.69 \%$ of glucose and $2.99 \%$ of xylose in the hydrolysed slurry obtained from enzymatic hydrolysis of bagasse. Cost-competitive ethanol yield from lignocellulose requires fermentation of both hexose and pentose constituents [29], so C5-C6 anaerobic co-fermentation was performed with an engineered strain of $Z$. mobilis TSH-01 under the condition optimized by our research team. For 36-h fermentation, a fermentation broth containing $4.3 \%$ of ethanol was obtained. The glucose conversion was $95.1 \%$ and the xylose conversion was $65.2 \%$. The lower conversion of xylose was attributed to the short fermentation time.

A mass balance starting from $10 \mathrm{~kg}$ of fresh sweet sorghum stalks for our overall process for ethanol yield is shown in Figure 7. In the enzymatic hydrolysis and C5-C6 co-fermentation stage, the data were converted according 

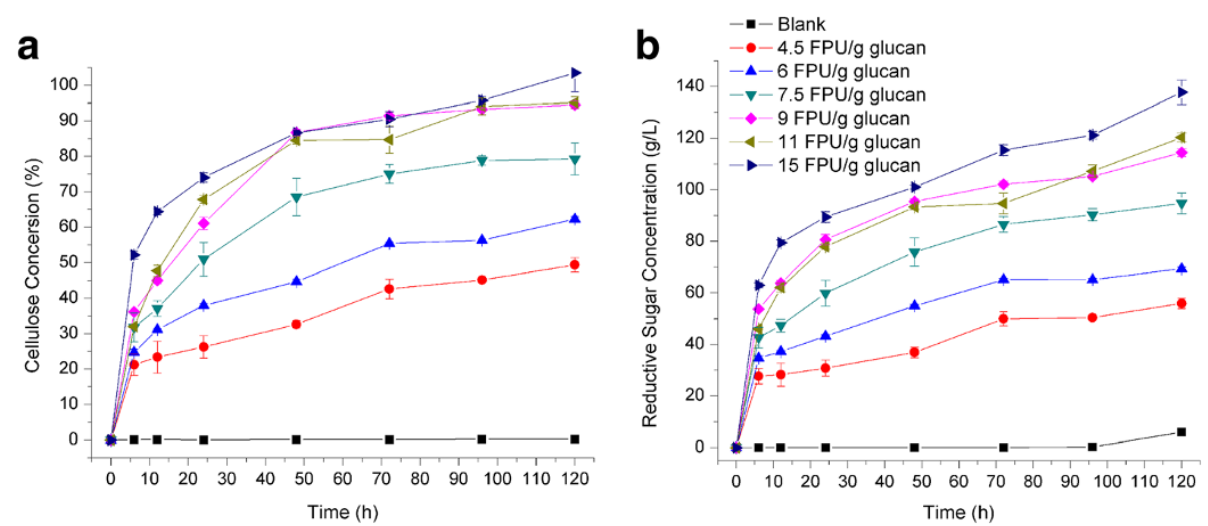

Figure 6 Enzymatic hydrolysis of sweet sorghum bagasse following various alkali pretreatments operated in a distillation stripper. a: Cellulose conversion of sweet sorghum bagasse following various alkali pretreatments; $\mathbf{b}$ : Reduction carbonhydrates concentration of hydrolysed solution of sweet sorghum bagasse following various alkali pretreatments. FPU, filter paper cellulase units.

to the results obtained from batch experiments performed in a shake flask instead of a large-scale instrument. It was found that $91.9 \mathrm{~kg}$ ethanol/tonne fresh sweet sorghum stalk was obtained, $62.7 \mathrm{~kg}$ ethanol from non-structural carbohydrates and $29.2 \mathrm{~kg}$ of ethanol from structural carbohydrates. In the solid fermentation step, the ethanol recovery was $87.7 \%$. In the cellulosic ethanol production step, there was $62.0 \%$ ethanol recovery due to the highest removal of xylan. The total ethanol recovery of the overall process was $71.55 \%$. Although the ethanol recovery was not high, the ethanol yield was $328 \mathrm{~kg}$ ethanol /tonne dry sweet sorghum stalk. This value was higher than the

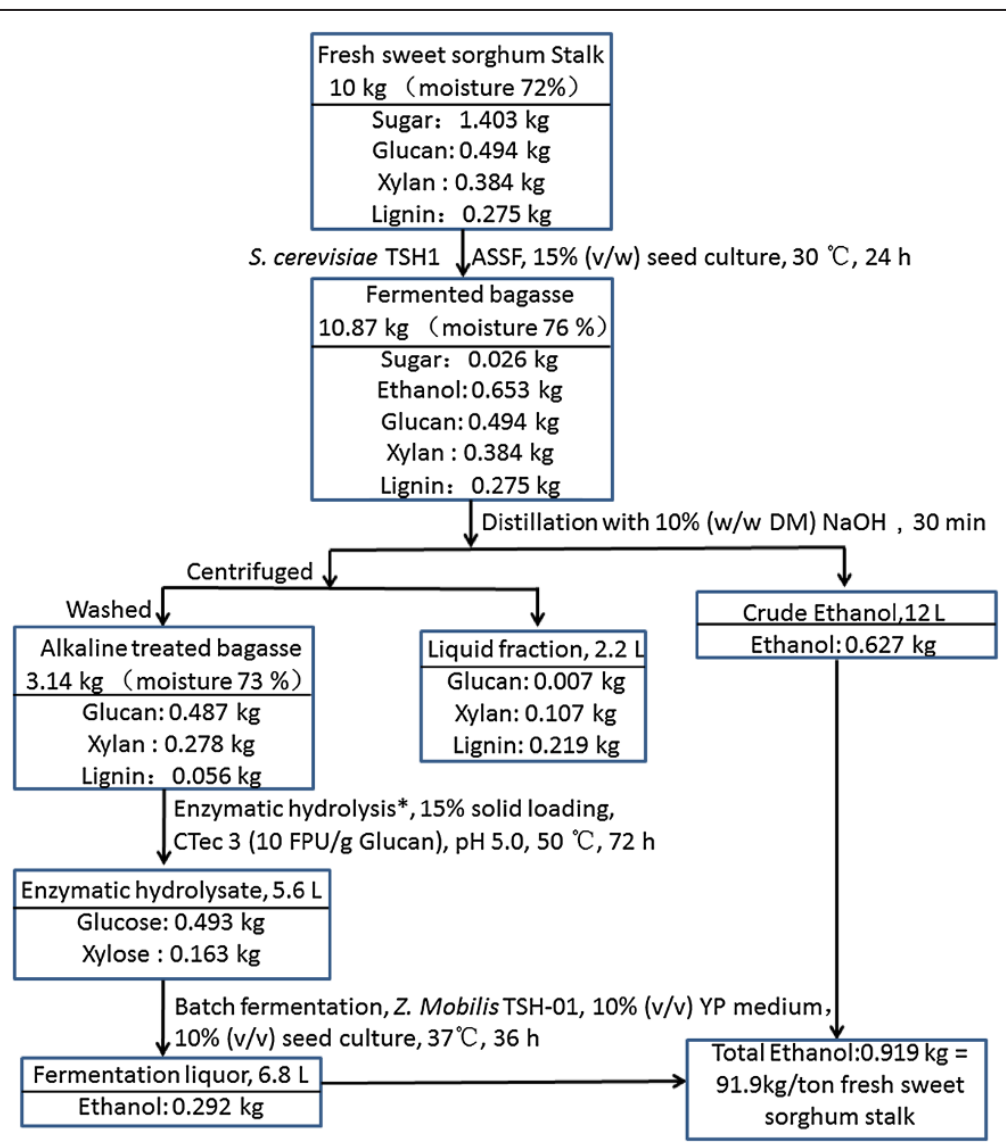

Figure 7 Mass balances for novel cost-efficient integrated processes for ethanol production from sweet sorghum stalks. ASSF, advanced solid-state fermentation technology; $\mathrm{NaOH}$, sodium hydroxide; DM, dry mass; FPU, filter paper cellulase unit. 
average cellulosic ethanol yield of $300 \mathrm{~kg} /$ tonne of biomass [30] and the soluble sugar ethanol yield of $280 \mathrm{~kg} /$ tonne [22]. The energy input and output of this novel process was also calculated and the results are shown in Table 4. To produce 1 tonne of ethanol, the energy input in our process was 12,481.2 MJ/tonne, and the energy input in other cellulosic ethanol processes is from 17,430 to $33,330 \mathrm{MJ} /$ tonne [31].

Analysis based on 1 tonne 99.5\% ethanol. ancluded process water, effluent restoration, capital equipment. Based on average of Energy and Resources Group (ERG) Biofuel Analysis Meta-Model (EBAMM) spreadsheet of Farrell [32].

\section{Conclusion}

In the present study, a novel low-energy consumption process for ethanol production involving first and second ethanol production from sweet sorghum was designed based on distillation combined with an alkali pretreatment process. $\mathrm{NaOH}$ loading of $10 \%$ (w/w DM) was determined as optimum in the pretreatment combined with the distillation step. Enzyme loading of $10 \mathrm{FPU} / \mathrm{g}$ of glucan during $72 \mathrm{~h}$ was selected for the enzymatic hydrolysis step. Enzyme loading of $10 \mathrm{FPU} / \mathrm{g}$ of glucan, and hydrolysis time of $72 \mathrm{~h}$ was confirmed in the enzymatic hydrolysis step: $91.9 \mathrm{~kg}$ of ethanol/tonne of fresh sweet sorghum stalk was obtained in the present work. Extraction of sweet sorghum juice, which has high energy-consumption, was avoided in our novel process. Energy and time consumption for pretreatment of sweet sorghum bagasse was also avoided by combining the pretreatment step and the first-

\begin{tabular}{|c|c|c|c|c|}
\hline \multirow{2}{*}{$\begin{array}{l}\text { Process } \\
\text { Smash }\end{array}$} & \multicolumn{2}{|l|}{ Input (MJ) } & \multicolumn{2}{|c|}{ Output (MJ) } \\
\hline & Electricity & 327.1 & & \\
\hline \multirow[t]{2}{*}{ Preheat } & Electricity & 80.6 & & \\
\hline & Vapor & 58.6 & & \\
\hline \multirow[t]{2}{*}{ Seed culture } & Electricity & 147.4 & & \\
\hline & Vapor & 58.6 & & \\
\hline \multirow[t]{2}{*}{ Fermentation } & Electricity & 209.2 & & \\
\hline & Reaction heat & 502.0 & & \\
\hline \multirow[t]{2}{*}{ Stripper } & Electricity & 60.9 & & \\
\hline & Steam & $7,561.3$ & Ethanol & $20,163.0$ \\
\hline Certification & Electricity & 65.3 & Lignin & $5,386.5$ \\
\hline $\begin{array}{l}\text { Enzymatic saccharification } \\
\text { and fermentation }\end{array}$ & Electricity & 761.6 & & \\
\hline Distillation and separation & Electricity & $2,437.1$ & Ethanol & $9,388.5$ \\
\hline Other biorefinery ${ }^{\mathrm{a}}$ & & 380.8 & & \\
\hline Total & & $12,650.5$ & & $34,938.0$ \\
\hline
\end{tabular}

generation ethanol distillation step in one step in one reactor, so the capital cost for the pretreatment reactor was also saved. This novel process is efficient to reduce the ethanol production cost and implement bioconversion of all carbohydrates in sweet sorghum stalks. Based on this technology, the recalcitrance of lignocellulose was destructed and the biodegradation of lignocellulose into fermentable sugar is feasible. Bioconversion of sweet sorghum bagasse into different product such as biogas, butanol, and chemicals from fermentation of sugar was feasibly performed under low-energy consumption conditions, so it is considered a promising process for a sugarbased lignocellulosic resource, such as sweet sorghum and sugarcane.

\section{Methods}

\section{Biomass}

Sweet sorghum, Chuntian 2\#, was harvested in October 2011, in Huanghua country, Hebei province. Leaves and husks were stripped by hand. The stem was crushed into particles of 1 to $2 \mathrm{~mm}$ in diameter, and 3 to $20 \mathrm{~mm}$ in length by pulverization, and was stored in sealed plastic bags at $-20^{\circ} \mathrm{C}$. Feedstock composition was determined using the National Renewable Energy Laboratory (NREL) standard Laboratory Analytical Procedures (LAP) for the determination of the composition of biomass [33]. The composition of the fresh stem is listed in Table 5. All chemicals used in the study were reagent grade and used directly from purchase.

\section{Microorganism}

S. cerevisiae TSH1 was used as the fermentation strain in the solid fermentation step. The microorganism was conserved in yeast extract peptone dextrose (YPD) medium at $4^{\circ} \mathrm{C}$ ( $1 \%$ yeast extract, $2 \%$ peptone, $2 \%$ glucose). In order to maintain the viability of the strain, the microorganism was sub-cultured before each experiment. An engineered Z. Mobilis TSH-01 recombined by Tsinghua University was used as the fermentation strain in the C5-C6 cofermentation step. The microorganism was conserved in RM culture medium at $4^{\circ} \mathrm{C}(1 \%$ yeast extract, $0.2 \%$ monosodium phosphate $\left(\mathrm{NaH}_{2} \mathrm{PO}_{4}\right), 2 \%$ glucose). In order to maintain the viability of the strain, the microorganism was sub-cultured before each experiment.

\section{Enzymes}

Enzymatic hydrolysis was carried out using the commercial enzyme Cellic CTec2 or Cellic CTec3, both kindly provided by Novozymes investment Co. Ltd (Beijing, China). The enzymatic activity was measured with Whatman No.1 filter paper according to the NREL method [32]. The filter paper enzymatic activity was 113 FPU/mL and $213 \mathrm{FPU} / \mathrm{mL}$ for Cellic CTec2 or Cellic CTec3, respectively. 
Table $\mathbf{5}$ Composition analysis of the sweet sorghum stalk

\begin{tabular}{lll}
\hline Component & Wet biomass \% & Dry biomass \% \\
\hline Sugar & $14.03 \pm 0.22$ & $50.10 \pm 0.78$ \\
Glucan & $4.94 \pm 0.05$ & $17.64 \pm 0.18$ \\
Xylan & $3.38 \pm 0.04$ & $12.07 \pm 0.14$ \\
Acid soluble lignin & $0.91 \pm 0.01$ & $3.26 \pm 0.05$ \\
Insoluble lignin & $1.84 \pm 0.01$ & $6.56 \pm 0.04$ \\
Ash & $0.09 \pm 0.00$ & $0.33 \pm 0.02$ \\
Others & 2.88 & 10.37 \\
\hline
\end{tabular}

The moisture of the sweet sorghum stalk is $72 \%$. All data are shown as mean \pm SD.

\section{Advanced solid-state fermentation}

Around $10 \mathrm{~kg}$ of crushed sweet sorghum was fully blended with $15 \%(\mathrm{v} / \mathrm{w})$ of TSH1 seed (about $25 \mathrm{~g} / \mathrm{L}$, dry weight) and loaded onto $50 \mathrm{~L}$ fermenter, $0.7 \mathrm{~m}$ in length and $0.3 \mathrm{~m}$ in diameter, designed by our laboratory. The fermentation was carried out at $30^{\circ} \mathrm{C}$ for $24 \mathrm{~h}$ with a rotary speed at $0.5 \mathrm{rpm}$. Samples were collected at the start and end points of fermentation. Ethanol concentration was determined by gas chromatography (GC). Sugar concentration was determined by high-performance liquid chromatography (HPLC).

\section{Distillation combined with alkaline pretreatment Preliminary experiments of distillation combined with alkaline pretreatment}

In order to investigate the effect of alkali loading on the pretreatment, a certain amount of fermented sweet sorghum bagasse was mixed with a certain amount of alkali to achieve the expected loading dose according to the values listed in Table 6 , and then the mixture was distilled in a 500-mL round-bottom flask for 30 minutes, which started when the first drop of distillate was observed. Then, $100 \mathrm{~mL}$ of distillate were collected to determine the ethanol-recovery yield. All the experiments were performed in duplicate. The solid residues were washed with distilled water until the $\mathrm{pH}$ value was 7.0 and dried in an oven at $50^{\circ} \mathrm{C}$. The dry weight and the composition of the bagasse following alkaline pretreatment were analyzed by the NREL method [33,34].

Distillation combined with $\mathrm{NaOH}$ pretreatment performed in a distillation stripper

Around $4 \mathrm{~kg}$ of fermented bagasse were mixed completely with $250 \mathrm{~mL}$ of $\mathrm{NaOH}(8 \mathrm{~mol} / \mathrm{L})$ concentrated solution, which provided the final alkali loading of $10 \%$ (w/w DM). The final moisture content was $76.3 \%$. This mixture was loaded into a 50 - $\mathrm{L}$ distillation stripper, $0.45 \mathrm{~m}$ in height, and $0.4 \mathrm{~m}$ in diameter, designed by our laboratory. Then, $0.15 \mathrm{MPa}$ of steam was injected into the distillation stripper. The monitored operating temperature was kept at
Table 6 The loading dose of different alkalines used in the distillation

\begin{tabular}{llll}
\hline $\begin{array}{l}\text { Loading dose } \\
\text { (mmol/g dry biomass ) }\end{array}$ & $\mathbf{N a O H}(\mathbf{g})$ & $\mathbf{K O H}(\mathbf{g})$ & $\mathbf{C a}(\mathbf{O H})_{\mathbf{2}}(\mathbf{g})$ \\
\hline 0.83 & 0.50 & 0.70 & 0.93 \\
1.67 & 1.00 & 1.40 & 1.85 \\
2.50 & 1.50 & 2.10 & 2.80 \\
3.33 & 2.00 & 2.80 & 3.70 \\
4.17 & 2.50 & 3.50 & 4.60 \\
5.00 & 3.00 & 4.20 & 5.60 \\
6.67 & 4.00 & 5.60 & 7.40 \\
\hline
\end{tabular}

The dry mass of sweet sorghum bagasse is $15 \mathrm{~g}$ and the water is $250 \mathrm{~g}$ in the distillation experiments. $\mathrm{NaOH}$, sodium hydroxide; $\mathrm{KOH}$, potassium hydroxide; $\mathrm{Ca}(\mathrm{OH})_{2}$, calcium hydroxide.

$100^{\circ} \mathrm{C}$ during the distillation stage. The operation time was 30 minutes, which started at the moment when the first drop of the distillate was observed. Another $4 \mathrm{~kg}$ of fermented bagasse without alkali was distilled as a control. The distillate was collected and ethanol concentration was analyzed by GC.

Following treatment the solid residues were centrifuged to remove the black liquor fraction and were washed by tap water (until the $\mathrm{pH}$ was 7.0) as required. The wet solid sample was stored in sealed plastic bags at $-20^{\circ} \mathrm{C}$. Some of it was dried in an oven at $50^{\circ} \mathrm{C}$ to determine the moisture and composition.

\section{Enzymatic hydrolysis}

Enzymatic hydrolysis of sweet sorghum bagasse followed the preliminary experiment of distillation combined with alkali pretreatment. Enzymatic hydrolysis of sweet sorghum bagasse following pretreatment was carried out in a 100 -mL shake flask, using $50 \mathrm{mM}$ sodium citrate buffer $(\mathrm{pH}=5.0)$ at $50^{\circ} \mathrm{C}$ and $120 \mathrm{rpm}$ for $72 \mathrm{~h}$. Sodium azide (3 g L-1) was added to inhibit microbial growth: $1 \mathrm{~g}$ of dry biomass was added in each flask, and then the buffer solution was added to the final solid concentration of 5\% (w/ w). Cellulase used in enzymatic hydrolysis was a commercial cellulase mixture, Cellic CTec2 (113 FPU/mL). The cellulase loading was $20 \mathrm{FPU} \mathrm{g}^{-1}$ of glucan. After enzymatic hydrolysis, $1 \mathrm{~mL}$ of the sample was taken from reaction mixture and centrifuged at $10,000 \mathrm{rpm}$ for 10 minutes. The supernatant was stored at $-20^{\circ} \mathrm{C}$ prior to HPLC analysis of reducing sugar concentration. All the experiments were performed in triplicate. One control experiment without cellulase was carried out to avoid the effect of residual sugars in sweet sorghum bagasse.

\section{Enzymatic hydrolysis of sweet sorghum bagasse} following distillation combined with alkaline pretreatment operated in a distillation stripper Enzymatic hydrolysis of sweet sorghum bagasse following pretreatment was carried out in a $500-\mathrm{mL}$ shake 
flask with 20 glass balls ( $4 \mathrm{~mm}$ in diameter), at $50^{\circ} \mathrm{C}$ and $150 \mathrm{rpm}$ for $120 \mathrm{~h}$. Then, $1 \mathrm{M}$ of sodium citrate buffer solution was added to the flask containing the washed bagasse, and distilled water was added until the final buffer concentration of $50 \mathrm{mM}$ and $\mathrm{pH}$ of 5.0 was obtained. The mixture was sterilized in an autoclave at $121^{\circ} \mathrm{C}$ for 30 minutes. Sterile water was added until the final solid loading was $15 \%(\mathrm{w} / \mathrm{w})$. The cellulase used in enzymatic hydrolysis was a commercial cellulase mixture, Cellic CTec3 (214 FPU/mL). Aliquots of the enzyme hydrolysates were taken at different time intervals (Figure 5) and the concentration of the reducing sugar in the hydrolysate was measured by HPLC. All the experiments were performed in triplicate. One control experiment without cellulase was carried out to determine the soluble sugars in the pretreated materials. This value as a blank was subtracted from the final sugar concentration after enzymatic hydrolysis, to calculate the glucan conversion yield.

The enzymatic hydrolysis of the washed bagasse, following distillation combined with $10 \%(\mathrm{w} / \mathrm{w}$ DM) $\mathrm{NaOH}$ treated in a distillation stripper for C5-C6 co-fermentation, was performed for $72 \mathrm{~h}$. Other conditions were the same as previously mentioned in this section. At end of hydrolysis, $0.5 \mathrm{~mL}$ of enzyme hydrolysate was taken out with a sterilized pipette and heated at $95^{\circ} \mathrm{C}$ for 5 minutes. The concentration of the reducing sugar in the hydrolysate was measured by HPLC. Ten parallel experiments were performed.

The glucan and xylan conversion achieved following enzymatic hydrolysis was calculated according to the following equations:

Glucan conversion $(\%)=\frac{\text { Glucose concentration } \times \text { Volume }}{\text { Glucan content of pretreated bagasse } \times 1.11} \times 100$

Xylan conversion $(\%)=\frac{\text { Xylose concentration } \times \text { Volume }}{\text { Xylan content of pretreated bagasse } \times 1.14} \times 100$

Volume is the volume of C5-C6 hydrolysed slurry.

\section{C5-C6 anaerobic co-fermentation of hydrolysed slurry}

As nutrient, $10 \%(\mathrm{v} / \mathrm{v})$ of concentrated YP (1\% yeast extract, $10 \%$ peptone) was added to the shake flask containing the hydrolysed slurry, and then the hydrolysed slurry was inoculated with $10 \%(\mathrm{v} / \mathrm{w})$ of $\mathrm{Z}$. Mobilis TSH-O1 seed (2.5 g/L dry weight). All the fermentations were performed at $37^{\circ} \mathrm{C}, \mathrm{pH} 6.0$, and $100 \mathrm{rpm}$ for $48 \mathrm{~h}$. Samples were taken at $0 \mathrm{~h}$ and $24 \mathrm{~h}$, centrifuged at 15,000 rpm, and $4^{\circ} \mathrm{C}$ for 10 minutes. The supernatant was stored at $-20^{\circ} \mathrm{C}$ for the sugar and ethanol measurement. Ten parallel experiments were performed.

\section{Analytical methods Dry matter}

Percent solids (\% TS) measurements were made using a $105^{\circ} \mathrm{C}$-oven method according to standard procedures developed at NREL [34].

\section{Sugar}

Sugar concentrations were measured using HPLC (Shimadzu LC-20 AD, Tokyo, Japan) equipped with a column (Bio-Rad HPX-87H, $250 \mathrm{~mm} \times 4.6 \mathrm{~mm}$, Beijing, China) operating at $60^{\circ} \mathrm{C}$ with a mobile phase of $5 \mathrm{mM}$ sulfuric acid $\left(\mathrm{H}_{2} \mathrm{SO}_{4}\right)$ aqueous solution with a flow rate of $0.5 \mathrm{~mL} /$ minute using a refractive index (RI) detector. Prior to analysis, the samples were diluted with ultrapure water, and then filtered through $0.45 \mathrm{~mm}$ filter (Millipore, Beijing, China).

\section{Ethanol}

Ethanol concentrations were determined by a gas chromatography (Shimadzu GC-14C, Japan) equipped with a flame ionization detector. A $0.125-\mathrm{cm}$ I.D., $2 \mathrm{~m}$, SS column was used using nitrogen gas $\left(\mathrm{N}_{2}\right)$ as a carrier gas and hydrogen gas $\left(\mathrm{H}_{2}\right)$ as a flaming gas. The injector temperature was $80^{\circ} \mathrm{C}$, and the detector temperature was $220^{\circ} \mathrm{C}$. The running time was 18 minutes.

\section{Abbreviations}

AlL: Acid insoluble lignin; ASL: Acid insoluble lignin; ASSF: Advanced solid-state fermentation technology; $\mathrm{Ca}(\mathrm{OH})_{2}$ : Calcium hydroxide; DM: Dry mass; EBAMM: Energy and Resources Group (ERG) Biofuel Analysis Meta-Model;

FPU: Filter paper cellulase unit; GC: Gas chromatography; HPLC: High performance liquid chromatography; $\mathrm{KOH}$ : Potassium hydroxide;

LAP: Laboratory Analytical Procedures; NaOH: Sodium hydroxide; NREL: National Renewable Energy Laboratory; RI: Refractive index; S. cerevisiae: Saccharomyces cerevisiae; TS: Total solid; WM: Wet mass; YPD: Yeast extract peptone dextrose; Z. mobilis: Zymomonas mobilis.

\section{Competing interests}

The authors declare that they have no competing interests.

\section{Authors' contributions}

$J L$ designed the experiments, conducted the pretreatment and wrote the manuscript. SL (Supervisor) conceived idea and edited the manuscript. BH conducted compositional analysis and enzymatic saccharification. MY and QL conducted ASSF. YJ conducted the carbohydrate analysis. All authors read and approved the final manuscript.

\section{Acknowledgements}

The study was supported by Ministry of Science and Technology of China (International scientific and technological cooperation projects, Grant No. 2013DFA60470 and 2012DFG61720), National Key Technologies R\&D Program of China (Grant No. 2011BAD22B03), and Low Carbon Energy University Alliance. We also thank Novozymes China Research Center for generously providing the cellulase.

Received: 21 June 2013 Accepted: 22 October 2013

Published: 29 November 2013

\section{References}

1. Bailey BK: Performance of ethanol as a transportation fuel. In handbook on bioethanol: production and utilization. Edited by Wyman CE. Washington DC: Taylor and Francis; 1996:37-60. 
2. Sipos B, Reczey J, Somorai Z, Kada Z, Dienes D, Reczey K: Sweet sorghumas feedstock for ethanol production: enzymatic hydrolysis of steampretreatedbagasse. App/ Biochem Biotechnol 2009, 153:151-162.

3. Ratnavathi C, Chakravarthy S, Komala V, Chavan U, Patil J: Sweet sorghum as feedstock for biofuel production: a review. Sugar Tech 2011, 13:399-407.

4. Matsakas L, Christakopoulos P: Optimization of ethanol production from high drymatter liquefied dry sweet sorghum stalks. Biomass Bioenerg 2013, 51:91-98.

5. FAO: Sweet sorghum in China. Rome, Italy: Food and Agriculture Organization of the United Nations (FAO); 2002.

6. Li SZ, Chan-Halbrendt C: Ethanol production in (the) People's Republic of China: potential and technologies. Appl Energy 2009, 86:S162-S169.

7. Gnansounou E, Dauriat A, Wyman CE: Refining sweet sorghum to ethanol and sugar: economic trade-offs in the context of North China. Bioresour Technol 2005, 96:985-1002.

8. Chohnan S, Nakane M, Rahman MH, Nitta Y, Yoshiura T, Ohta H, Kurusu Y: Fuel ethanol production from sweet sorghumusing repeated batch fermentation. J Biosci Bioeng 2011, 111:433-436.

9. Ratnavathi CV, Suresh K, Kumar BSV, Pallavi M, Komala W, Seetharama N: Study on genotypic variation for ethanolproduction from sweet sorghum juice. Biomass Bioenerg 2010, 34:947-952.

10. Wang EQ, Li SZ, Tao L, Geng X, Li TC: Modeling of rotating drum bioreactor for anaerobic solid-state fermentation. Appl Energy 2010, 87:2839-2845.

11. Yu ZL, Zhang $X$, Tan TW: Ethanol production by solid state fermentation of sweet sorghum using thermotolerant yeast strain. Fuel Process Technol 2008, 89:1056-1059.

12. Bryan WL: Solid-state fermentation of sugars in sweet sorghum. Enzyme and microb technol 1990, 12:437-442.

13. $\mathrm{Yu} J$, Zhong J, Zhang $X$, Tan T: Ethanol production from $\mathrm{H}_{2} \mathrm{SO}_{3}$ steampretreatedfresh sweet sorghum stem by simultaneous saccharification andfermentation. Appl Biochem Biotechnol 2010, 160:401-409.

14. Sun Y, Cheng J: Hydrolysis of lignocellulosic materials forethanol production: a review. Bioresour Technol 2002, 83:1-11.

15. Antizar-Ladislao B, Turrion-Gomez J: Second-generation biofuels and local bioenergy systems. Biofuels Bioprod Bior 2008, 2:455-469.

16. Agbor VB, Cicek N, Sparling R, Berlin A, Levin DB: Biomass pretreatment: fundamentals toward application. Biotechnology Adv 2011, 29:675-685.

17. Taherzadeh MJ, Karimi K: Pretreatment of lignocellulosic wastes to improve ethanol and biogas production: a review. Int J Mol Sci 2008, 9:1621-1651.

18. Xu J, Cheng JJ, Sharma-Shivappa RR, Burns JC: Sodium hydroxide pretreatment of switchgrass for ethanol production. Energy Fuels 2010, 24:2113-2119.

19. Zhang J, Ma X, Yu J, Zhang X, Tan T: The effects of four different pretreatments on enzymatic hydrolysis of sweet sorghum bagasse. Bioresour Technol 2011, 102:4585-4589.

20. Cao WX, Sun C, Liu RH, Yin RZ, Wu XW: Comparison of the effects of five pretreatment methods on enhancing the enzymatic digestibility and ethanol production from sweet sorghum bagasse. Bioresour Technol 2012, 111:215-221.

21. Billa E, Koullas DP, Monties B, Koukios EG: Structure and composition of sweet sorghum stalk components. Ind Crop Prod 1997, 6:297-302.

22. Li SZ, Li GM, Zhang L, Zhou Z, Han B, Hou W, Wang J, Li T: A demonstration study of ethanol production from sweet sorghum stems with advanced solid state fermentation technology. App/ Energy 2013, 102:260-265.

23. Mclntosh S, Vancov T: Ethanol enzyme saccharification of Sorghum bicolor straw using dilute alkali pretreatment. Bioresour Technol 2010, 101:6718-6727.

24. Gupta R, Lee $Y Y$ : Investigation of biomass degradation mechanism inpretreatment of switchgrass by aqueous ammonia and sodiumhydroxide. Bioresour Technol 2010, 101:8185-8191.

25. Rabelo SC, Filho RM, Costa AC: Lime pretreatment and fermentation of enzymatically hydrolyzed sugarcane bagasse. Appl Biochem Biotechnol 2013, 169:1696-1712.

26. Chen Y, Stevens MA, Zhu Y, Holmes J, Xu H: Understanding of alkaline pretreatment parameters for corn stover enzymaticsaccharification. Biotech for Biofuels 2013, 6:1-10.
27. Chang VS, Holtzapple MT: Fundamental factors affecting biomass enzymatic reactivity. Appl Biochem Biotechnol 2000, 84-86:5-37.

28. Laureno-Perez L, Teymouri F, Alizadeh H, Dale B: Understanding factors that limit enzymatic hydrolysis of biomass characterization of pretreated corn stover. Appl Biochem Biotechnol 2005, 124:1081-1099.

29. Gable M, Sassner P, Wingren A, Zacchi G: Process engineering economics of bioethanol production. Adv Biochem Eng/Biotechnol 2007, 108:303-327.

30. Lai YZ: Wood and Cellulose Chemistry. In Chemical Degradation. 2nd edition. Edited by Hon DNS, Shiraishi N. New York: Marcel Dekker Inc; 1991:455-473.

31. Zhu JY, Zhuang XS: Conceptual net energy output for biofuel production from lignocellulosic biomass through biorefining. Prog Energ Combust 2012, 38:583-598.

32. Farrell $A E$, Plevin RJ, Turner BT, Jones AD, O'Hare M, Kammen DM: Ethanol can contribute to energy and environmental goals. Science 2006, 311:506-508.

33. Sluiter A, Hames B, Ruiz R, Scarlata C, Sluiter J, Templeton D, Crocker D: Determination of structural carbohydrates and lignin in biomass: Laboratory Analytical Procedure; 2008. NREL/TP-510-42618. Updated 2010.

34. Sluiter A, Hyman D, Payne C, Wolfe J: Determination of total solids in biomass and total dissolved solids in liquid process samples. http://www.nrel.gov/biomass/pdfs/42621.pdf.

doi:10.1186/1754-6834-6-174

Cite this article as: Li et al:: A novel cost-effective technology to convert sucrose and homocelluloses in sweet sorghum stalks into ethanol. Biotechnology for Biofuels 2013 6:174.

\section{Submit your next manuscript to BioMed Central and take full advantage of:}

- Convenient online submission

- Thorough peer review

- No space constraints or color figure charges

- Immediate publication on acceptance

- Inclusion in PubMed, CAS, Scopus and Google Scholar

- Research which is freely available for redistribution

Submit your manuscript at www.biomedcentral.com/submit
C Biomed Central 